Review Article

\title{
A Novel Mechanism for Cross-Adaptation between Heat and Altitude Acclimation: The Role of Heat Shock Protein 90
}

\author{
Roy M. Salgado, Ailish C. White, Suzanne M. Schneider, and Christine M. Mermier \\ Department of Health, Exercise and Sports Sciences, University of New Mexico, Albuquerque, NM 87131, USA \\ Correspondence should be addressed to Christine M. Mermier; cmermier@unm.edu
}

Received 28 October 2013; Revised 4 April 2014; Accepted 9 April 2014; Published 12 May 2014

Academic Editor: Hanjoong Jo

Copyright (C) 2014 Roy M. Salgado et al. This is an open access article distributed under the Creative Commons Attribution License, which permits unrestricted use, distribution, and reproduction in any medium, provided the original work is properly cited.

\begin{abstract}
Heat shock protein 90 (HSP90) is a member of a family of molecular chaperone proteins which can be upregulated by various stressors including heat stress leading to increases in HSP90 protein expression. Its primary functions include (1) renaturing and denaturing of damaged proteins caused by heat stress and (2) interacting with client proteins to induce cell signaling for gene expression. The latter function is of interest because, in cancer cells, HSP90 has been reported to interact with the transcription hypoxic-inducible factor $1 \alpha(\mathrm{HIF} 1 \alpha)$. In a normoxic environment, HIF1 $\alpha$ is degraded and therefore has limited physiological function. In contrast, in a hypoxic environment, stabilized HIFl $\alpha$ acts to promote erythropoiesis and angiogenesis. Since HSP90 interacts with HIF1 $\alpha$, and HSP90 can be upregulated from heat acclimation in humans, we present a proposal that heat acclimation can mimic molecular adaptations to those of altitude exposure. Specifically, we propose that heat acclimation increases HSP90 which then stabilizes HIF1 $\alpha$ in a normoxic environment. This has many implications since HIF1 $\alpha$ regulates red blood cell and vasculature formation. In this paper we will discuss (1) the functional roles of HSP90 and HIF1 $\alpha$, (2) the interaction between HSP90 and other client proteins including HIF1 $\alpha$, and (3) results from in vitro studies that may suggest how the relationship between HSP90 and HIFl $\alpha$ might be applied to individuals preparing to make altitude sojourns.
\end{abstract}

\section{Introduction}

Heat shock proteins (HSP's) are classified as molecular chaperones that play an integral role in the maintenance of damaged cells after heat exposure. When a living organism is exposed to a hyperthermic environment, intracellular HSP expression is increased. A function of HSPs is to sequester and refold denatured proteins $[1,2]$, with an upregulation protecting cells from future thermal damage [3].

Heat shock protein 90 (HSP90) is a $90 \mathrm{kda}$ protein that has specific functional characteristics when compared to other members of the HSP family. Along with renaturing damaged proteins, HSP90 interacts with target client proteins stimulating the activation of specific signaling transduction pathways [4]. Specifically, in clinical research, HSP90 has been shown to participate in the signaling transduction of some proteins regulating oncogenic factors [5]. Research shows that HSP90 inhibitors have been examined in their role to decrease tumor growth [6] by interacting with hypoxicinducible factorl $\alpha(\mathrm{HIFl} \alpha)$. In this pathway, inhibition of
HSP90 leads to less bioavailable HIF1 $\alpha$ a transcription factor for vascular endothelial growth factor (VEGF) which promotes angiogenesis. An example of this interaction has been illustrated when geldanamycin (GA) an HSP90 inhibitor leads to degradation of HIFl $\alpha$ in tumor cells decreasing vascular growth [7]. The interaction between HSP90 and HIFl $\alpha$ provides an intriguing aspect of the regulation of HIFl $\alpha$.

In endurance athletics, training methods which involve the use of hypobaric hypoxia have been used to induce an increase in HIF1 $\alpha$ a transcription factor responsible for expression of erythropoiesis. With increasing altitude there is a decrease in the partial pressure of oxygen $\left(\mathrm{PIO}_{2}\right)$, which stabilizes HIF1 $\alpha$ causing activation of molecular signaling pathways needed in a low oxygen environment [8]. In a normal oxygen environment, HIFl $\alpha$ is constantly undergoing protein degradation, while, in hypoxia, HIFl $\alpha$ does not undergo protein degradation but leads to an increased bioavailability of the protein which is then considered stabilized. 
The idea that HSP90 interacts with HIF1 $\alpha$ is appealing for sports scientists because it may provide a novel crossacclimation training model in which heat acclimation (HA) may improve exercise tolerance at high altitude. Investigators have found that continuous exposure to high altitude (traditional altitude training) is the optimal method to induce altitude acclimation and to improve exercise capacity $[9,10]$ while intermittent high altitude (hypobaric hypoxia or normobaric hypoxia) exposure provides an alternative effective approach to altitude acclimation $[9,11]$. Limitations of both the traditional and intermittent altitude exposure are that individuals may not have (1) access to high altitude terrain, (2) time needed to spend at altitude for effective acclimation, or (3) the expensive equipment required to simulate hypoxia. Thus, an alternative approach such as HA may be beneficial to those needing to acclimate to hypoxic environments. The ability to exercise in hot environments is more accessible to most individuals than to exercise in hypoxic environment. Heat acclimation may be beneficial for those seeking to improve sea-level exercise performance or for use as crossacclimation model to maintain or improve exercise capacity at high altitude (defined as $\geq 2200 \mathrm{~m}$ ) without being exposed to high altitude.

The understanding of molecular adaptations to HA may lead to future sports sciences applications. Results from studies using in vitro models have found that inhibition of HSP90 limits HIFl $\alpha$ activity, suggesting that perhaps HA could stimulate HSP90 activity and stabilize HIF1 $\alpha$. Increases in HIF1 $\alpha$ may initiate some of the changes normally associated with altitude training such as increased red cell mass or increased collateral circulation.

The purpose of this paper is to discuss the possibility of using HA to induce some of the adaptations that occur with altitude acclimation. We will review in vitro research regarding the regulation of HIF1 $\alpha$ by HSP90 as a framework for proposing what may occur in humans. Stressors other than heat also increase the HSP90 response; however; in this review we will limit the discussion to only those associated with exercise and heat. We will discuss (1) the functional relationship between HSP90 and HIF1 $\alpha$ and (2) the interactions between HSP90 and client proteins which may alter exercise response. Lastly, we will discuss how we can use what we have learned from in vitro studies to deduce how this relationship between HSP90 and HIF1 $\alpha$ might be applied to humans exercising at high altitude training.

\section{Function of Heat Shock Protein 90}

Heat shock protein 90 is ubiquitously expressed [12] and acts to preserve damaged proteins from being denatured; thus HSP90 is considered a housekeeping protein important in the maintenance of cellular homeostasis. In addition, HSP90 appears to interact with and activate client proteins such as numerous steroid receptors including glucocorticoid and androgen receptors $[13,14]$. In some cases, activation of some of these client proteins may lead to cellular growth such as cancer and tumor growth. The transcriptional regulation of this protein is by heat shock factor 1 (HSF1). Using an affinity chromatography technique, Nadeau and colleagues [15] were the first to show that HSP90 formed a protein-to-protein complex with HSF1 (HSP90-HSF1 complex). Subsequently, in vitro studies using human HeLa cells provided the first evidence that HSP90 regulated its own transcription activity [16]. In subsequent in vivo studies, oocytes of Xenopus laevis frogs injected with HSP90 antibody disrupted the HSP90HSF1 complex leading to an increase of HSF1 binding to the heat shock element (HSE) of the DNA promoter region $[17,18]$. Empirical evidence supports the notion that HSP90 is transcriptionally regulated by HSF1. In this section, HSP90's functional role in protein sequestering and activation of other proteins will be discussed.

2.1. HSP90's Role in Protein Maintenance. Heat shock protein 90 is an elongated dimer protein in which the C-termini are connected in the middle of the protein with the N-termini located at distal ends [4]. When activated, the N-termini of the protein act as a clamp surrounding the target protein sequestering and refolding damaged proteins $[4,19]$. This was observed in an in vitro study when denatured citrate synthase was treated with varying concentrations of HSP90 [19]. Wiech et al. [19] reported fewer protein aggregates and greater functional proteins after refolding when HSP90 was present compared to when proteins were not treated with HSP90. When luciferase is denatured, attenuation of protein aggregates was reported when treated with HSP90 and then compared without the treatment of HSP90 [20, 21]. One method in which researchers have studied the effects of HSP90 on protein refolding is by inhibiting HSP90.

Geldanamycin is an HSP90 inhibitor which binds to the active site of HSP90 inhibiting ATP hydrolysis, thus decreasing activation of the protein. When GA is added to HSP90 and denatured luciferase, there is a 50\% decrease in protein refolding [20]. Schneider et al. [22] investigated the effects of heat-induced denatured colon and breast carcinoma cells treated with and without GA. The investigators reported $\sim 85 \%$ and $\sim 52 \%$ increase in protein activity and protein refolding, respectively, in cells not treated with GA [22]. The reported decrease in protein refolding suggests GA's efficacy in the inhibition of HSP90. Thulasiraman and Matts [23] also reported that protein renaturing of luciferase in rabbit reticulocytes is inhibited in a dose-dependent manner $(0.2$ to $1.3 \mu \mathrm{M}$ of $\mathrm{GA}$ ), with the maximum inhibiting dose being $0.7 \mu \mathrm{M}$ of GA.

In summary, HSP90 acts to sequester and refold proteins that have been damaged during heat stress. The role of HSP90 to refold denatured proteins is illustrated when there is a decrease in protein refolding and function after inhibition by GA. The results from these studies provide support that HSP90 plays a role in damaged protein rebuilding. Additionally, HSP90 also appears to interact and activate client proteins which can lead to activation of cell signaling pathways. In the next section, HSP90's role in interacting with client proteins will be discussed.

2.2. Interaction between HSP90 and Client Proteins. Along with acting as a molecular chaperone to refold denatured 
proteins after heat stress, HSP90 also interacts with client proteins [24]. Its functional role in interacting with client proteins is to bind to and form a complex with proteins which can induce signal transduction $[25,26]$. Among these client proteins are steroid receptors [27], dioxin receptors [28, 29], and nitric oxide synthase (Figure 3 ). In this section, we will discuss the physiological effects of the interaction between HSP90 on specific client proteins.

2.3. HSP90 and Glucocorticoid. Studies have shown that HSP90 is capable of binding to steroid receptors [30, 31]. The importance of HSP90 binding to hormone receptors is that it allows for translocation into the nucleus, subsequently activating gene expression. In glucocorticoid receptors (GR), the HSP90 bound to GR forms a HSP90-GR complex which maintains the GR conformation allowing for ligand binding [32]. Disruption of the HSP90-GR complex can lead to a decrease receptor to ligand affinity $[32,33]$. Inhibition of HSP90 decreases steroid receptor activation and may lead to decreased signal transduction as reported in in vitro [34, 35] and in vivo [35] studies. Segnitz and Gehring [34] examined the effects of GA on different steroid receptors and reported an $8.7 \%$ increase in enzyme activity when glucocorticoid was administered to $3 \mathrm{~T} 3$ fibroblast cells. In contrast enzyme activity was reduced 1.2-fold when cells were then treated with GA. When cells were no longer treated with GA, enzyme activity and steroid receptor induction was regained. The physiological consequence of HSP90-GR complex disruption can be profound. Using in vivo mouse model, Bucci et al. [36] investigated the effects of HSP90 inhibition on carrageenaninduced inflammation. The authors reported that cotreatment of both dexamethasone (an anti-inflammatory) and GA had no effect on reducing inflammation. It was concluded that GA disrupted the anti-inflammatory effect of dexamethasone by decreasing receptor-ligand binding affinity. Other HSP90 inhibitors also have shown similar results. Solit et al. [35] reported that in vivo $500 \mathrm{~nm}$ of 17-AAG decreased androgen receptor by $\sim 91 \%$ in human prostate cancer cells. The authors reported a dose-response relationship where there were $87 \%$ and $80 \%$ decrease in androgen receptor activity and tumor growth when mice with prostate cancer were treated with $50 \mathrm{mg} / \mathrm{kg} 17-\mathrm{AAG}$.

2.4. HSP90 and Aryl Hydrocarbon Receptor. Heat shock protein 90 interacts with aryl hydrocarbon receptor (AHR) (also known as dioxin receptor). Aryl hydrocarbon receptor is a transcription factor [37] that regulates the synthesis of cytochrome P450 enzymes within the liver. Among other roles, cytochrome $\mathrm{P} 450$ enzymes are responsible for metabolism of drugs [38, 39], vitamins [40, 41], and cholesterol [41]. In the cytoplasm, when AHR is not bound to a protein it is bound to HSP90, forming an HSP90-AHR complex [42]. Formation of this complex is important in the AHR activity. Research has revealed that disruption or low levels of HSP90 enough to limit HSP90-AHR complex would decrease ligand-to-AHR binding ultimately leading to less active AHR [43, 44]. Whitelaw et al. [44] modified yeast strain to express low HSP90 binding receptors on the AHR.
This technique limits the formation of HSP90-AHR complex, so that protein interaction can be investigated. The researchers reported less active AHR activity when treated with an AHR agonist $\beta$-naphthoflavone in the modified AHR. In order for a protein to bind to AHR, the HSP90AHR complex must first be present indicating HSP90 signal responsiveness. Others have also shown that HSP90-AHR complex is required for high-affinity binding of ligand-toAHR binding $[45,46]$.

2.5. HSP90 and Nitric Oxide. Nitric oxide synthase (NOS) is an enzyme that oxidizes L-arginine to citrulline and the by-product of that reaction is nitric oxide (NO) [47]. Nitric oxide is a potent vasodilator responsible for dilating pulmonary and peripheral vascular smooth muscle to increase blood flow. The physiological significance of the HSP90-NOS interaction has been illustrated when inhibition of HSP90 by GA significantly decreases vasodilatation in the aorta of rats [48]. The antivasodilatory effect of GA on peripheral vasculature also has been reported in vivo. Shastry and Joyner [49] investigated the effects of GA on peripheral vascular blood flow in humans and reported that GA reduced vascular blood flow when vasodilation was induced separately by acetylcholine and local heat to the skin.

Heat shock protein 90 plays a role in the regulation of all three isoforms of NOS (inducible NOS, epithelial NOS, and neuronal NOS) [47]. The mechanism of action has not been fully elucidated, but it appears that HSP90 interacts with NOS by stabilizing and increasing the affinity of calcium to the calcium-calmodulin complex [50]. When kidney cells (HEK293) were treated in a physiological range from 10 to $500 \mathrm{nM}$ with HSP90, iNOS activity (measured by L-arginine to citrulline conversion) significantly increased in a dosedependent manner [51]. This dose-dependent response of HSP90 on NOS activity has also been reported in the nNOS isoform [50] and increased presence of HSP90 has been shown to increase all three isoforms of NOS activity and to subsequently increase formation of $\mathrm{NO}[48,51]$.

Collectively, the results from these investigations illustrate that HSP90 interacts with and can increase activity of NOS. Activation and upregulation of NOS can lead to downstream signal transduction causing vasodilation. Inhibition of HSP90 can attenuate the physiological responses by decreasing the signal transduction to decrease vasodilatory responses.

2.6. HSP90's Role in Vascular Growth. Vascular growth is mediated by the transcription factor VEGF which is regulated by HIF1 $\alpha[52,53]$. Increased expression of VEGF leads to angiogenesis or formation of new blood vessels. Blockade of the hypoxic response element (HRE) of HIFl $\alpha$ on DNA has a downstream effect of decreasing VEGF [52]. In this section we review supporting evidence that HSP90 regulates HIF1 $\alpha$ and therefore VEGF

Cancer growth is dependent on an increased vasculature which provides optimal nutrient delivery and blood flow. The upregulation of HSP90 in cancer cells plays a role in mediating cancer growth by inducing increases in HIFl $\alpha$ 
and VEGF [54]. Evidence supporting this relationship is observed when HIFl $\alpha$ and VEGF protein levels are decreased by the administration of GA in prostate cancer cells [55]. Research shows that HIF1 $\alpha$ and VEGF protein levels are increased in cancer cells [56, 57]. Giatromanolaki et al. [58] reported that $33 \%$ of 106 subjects with multiple myeloma had higher levels of HIFl $\alpha$ protein in the cytoplasm and nucleus of bone marrow samples. The high levels of HIF1 $\alpha$ were linked with greater VEGF and vascular density. Further, Büchler et al. [59] took biopsy samples of 18 human patients with pancreatic cancer and exposed the samples to a low oxygen environment $\left(\geq 90 \% \mathrm{~N}_{2}\right.$ and $\left.\geq 5 \% \mathrm{CO}_{2}\right)$. The authors found that HIF1 $\alpha$ protein and VEGF mRNA significantly increased in a time-dependent manner. It is noteworthy that characterization of cancerous pancreatic tissues revealed that, even when exposed to a normoxic environment, detectable levels of HIFl $\alpha$ and VEGF were observed [59]. This has been supported when human prostate cancer cells cultured in normoxic conditions $\left(20 \% \mathrm{O}_{2}\right.$ and $\left.5 \% \mathrm{CO}_{2}\right)$ expressed HIFl $\alpha$ mRNA, while this expression was not observed in noncancerous tissues [60]. It can be concluded that other factors may regulate HIFl $\alpha$ in a normoxic environment. Traditionally, activation of the HIF1 $\alpha$ signaling pathway is dependent on a hypoxic environment, allowing for stabilization of the protein. The presence of measurable proteins suggests that cytosolic HIFl $\alpha$ may be regulated in a normoxic environment in these cells.

\section{Function of Hypoxic-Inducible Factor $1 \alpha$}

Hypoxic-inducible factor $1 \alpha$ is classified as an oxygen sensing molecule. In a normoxic environment, HIFl $\alpha$ is ubiquitinated via prolyl-hydroxylase (PHD). After HIF1 $\alpha$ protein is tagged by PHD's it is degraded via E3 ligase of the von Hippel-Lindau (vHL) proteasomal pathway [8]. In a hypoxic environment, PHD levels are decreased preventing vHL protein degradation of HIF1 $\alpha$. Instead, HIFl $\alpha$ is translocated across the nucleus where it dimerizes with HIFl $\beta$ forming the active form of HIF1 transcription factor [8]. Hypoxicinducible factor 1 will bind to the HRE on the nuclear DNA signaling activation of many transcription factors that cause adaptations in order to maintain homeostasis in a low oxygen environment. The signaling pathway is summarized in Figure 1. Interestingly, in prostate cancer cells, HIFl $\alpha$ mRNA expression is upregulated when tissue samples were cultured in normal oxygen levels [60]. The presence of this protein can lead to a signaling cascade similar to that observed when cells are placed in a hypoxic environment. Stabilization of HIF1 $\alpha$ in normoxia indicates an alternative regulator of HIFl $\alpha$ in normal oxygen environment. In fact, stabilization of HIFl $\alpha$ appears to involve the molecular chaperone HSP90.

3.1. HSP90/HIF1 Interaction. As previously discussed, one function of HSP90 is to interact with and activate client proteins [24]. A method commonly used to determine proteinto-protein interaction is through coimmunoprecipitation. This method involves the lysing of cells without denaturing intracellular proteins. An antibody specific to the protein-toprotein complex is then added and the protein complex is then measured using western blot technique. Greater protein expression of the coimmunoprecipitate indicates protein-toprotein interaction. A client protein that has been found to interact with HSP90 is HIF1 $\alpha[61,62]$. Gradin et al. [63] showed greater HSP90-HIF1 $\alpha$ protein interaction in rabbit reticulocyte lysate coimmunoprecipitated in HSP90 compared to the control without HSP90. Isaacs et al. [61] also reported an increase in HSP90-HIFl $\alpha$ interaction when precipitate was measured in prostate (C2) and kidney (CAKI1) cells. Interestingly, this protein interaction can be disrupted by treating cells with HSP90 inhibitors $[61,62]$. The mechanism of protein disruption may be due to inactivation of the ATP binding site of HSP90, decreasing its ability to act on client proteins [7]. Some researchers claim that, since GA induces HIF1 $\alpha$ protein degradation, HSP90/HIF1 $\alpha$ interaction is required for HIFl $\alpha$ stability in a normoxic environment.

The physiological significance of the HSP90-HIF1 $\alpha$ interaction has not been fully elucidated $[62,63]$ but interference of HSP90 with HSP90 inhibitors leads to diminished cancer growth [6], while increases HSP90-HIFl $\alpha$ precipitate promotes angiogenesis. Heat shock protein 90 interaction with HIFl $\alpha$ allows stabilization of HIF rather than undergoing protein degradation in normoxia [64].

\section{Hypoxia's Role in Regulating Angiogenesis and Erythropoiesis}

At altitude there is a decrease in the $\mathrm{PIO}_{2}$ reducing oxygen delivery to the working muscles which results in decreased exercise performance $[65,66]$. To combat a low oxygen environment, the body adapts to maintain normal function. An adaptive response is to increase oxygen delivery by increasing the number/density of blood vessels (increased capillary density) or to increase oxygen-carrying capacity (polycythemia, increase red blood cell) which is mediated by the HIFl $\alpha$ pathway. In this section we will discuss how hypoxia regulates angiogenesis and erythropoiesis.

Exercising in a hypoxic environment or severe hypoxic exposure alone can induce molecular adaptations that are mediated by transcription factors that stimulate angiogenesis [67] and increase the EPO response [67, 68]. To study the molecular adaptations of endurance exercise at simulated hypoxia $(3850 \mathrm{~m})$, Vogt et al. [69] divided 30 untrained male subjects into four groups: (1) normoxic high-exercise intensity group, (2) hypoxic high-exercise intensity group, (3) normoxic low-exercise intensity group, and (4) hypoxic low exercise intensity group. Low- and high-exercise intensity workloads were defined as the workload (watts) corresponding to 2-3 mM and 4-6 $\mathrm{mM}$ of blood lactate, respectively, and were performed five days a week for 30 minutes. Those in the hypoxic group wore a facemask and breathed inspired oxygen of a $\mathrm{PIO}_{2}$ equating to $89 \mathrm{mmHg}$ to simulate $3850 \mathrm{~m}$. Researchers reported significant $82.4 \%$ and $58.2 \%$ increase in HIF $1 \alpha$ mRNA expression in both hypoxic groups, independent of exercise intensity while there was a $17 \%$ increase 


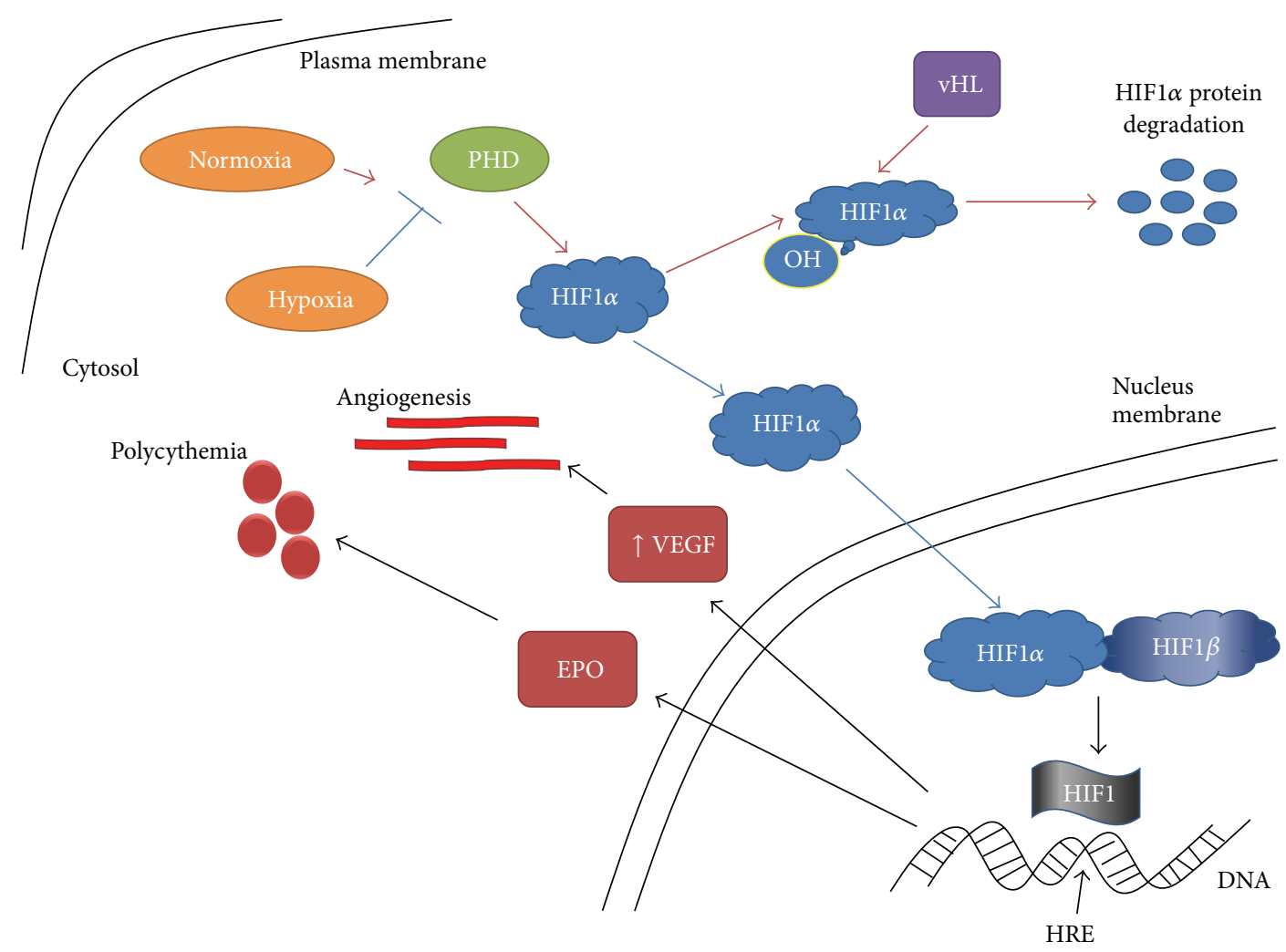

FIGURE 1: In normoxia, HIFl $\alpha$ is hydroxylated by PHD. Hydroxylated HIF1 $\alpha$ undergoes protein degradation via vHL proteasome pathway. In hypoxia, PHD does not hydroxylate HIFl $\alpha$. Stabilized HIF1 $\alpha$ is translocated across nucleus membrane dimerizing with HIF1 $\beta$. Dimerization of HIF1 $\alpha / \beta$ increases HIF1 transcription factor which binds to HRE of DNA. This increases VEGF and EPO production. HIF1 $\alpha$ : hypoxicinducible factor $1 \alpha / \beta$; PHD: prolyl-hydroxylase; vHL: von Hippel-Lindau; VEGF: vascular endothelial growth factor; HRE: hypoxic response element.

in the normoxic high intensity group and no changes in the normoxic low intensity group derived from muscle biopsies of the vastus lateralis. Researchers also reported a $52.4 \%$ increase in VEGF mRNA, as well as an $18.7 \%$ increase in muscle capillary length in the hypoxic high intensity exercise group. It is, however, important to note that changes in VEGF mRNA and capillary length were only observed in the hypoxia high intensity exercise group. The authors concluded that a greater exercise stimulus may have aided in greater VEGF mRNA expression and therefore increased capillary length. Nevertheless, angiogenesis has been observed after 3 and 6 weeks of continuous exposure to hypoxia $\left(12 \% \mathrm{O}_{2}\right)$ alone [70, 71].

Semenza and colleagues [72, 73] have shown that hypoxia-induced HIFl $\alpha$ regulates the release of erythropoietin (EPO) in the kidneys. A significant increase in serum-EPO has been observed when humans were acutely $(5.5 \mathrm{~h})$ exposed to simulated hypobaric hypoxia $(3,000$ and $4,000 \mathrm{~m})$ [74]. Researchers also reported an inverse relationship between serum-EPO and alveolar partial pressure of oxygen $\left(\mathrm{PAO}_{2}\right)$. This meant that, at a lower $\mathrm{PAO}_{2}$, it was shown that there was a greater presence of serumEPO, a result which has been supported by others $[75,76]$. Erythropoietin is a hormone released in the blood stream which travels to bone marrow stimulating red blood cell formation [77]. This leads to an increase in oxygen-carrying capacity that is necessary to maintain exercise capacity during high altitude sojourns.

The idea that HIFl $\alpha$ may be stabilized in normoxic environmental conditions presents a possible novel approach to induce molecular adaptations beneficial for exercise in a hypoxic environment. Heat shock protein 90 is an abundant protein found in the cytoplasm [78] that is ubiquitously expressed throughout cells [12]. Thus, this idea brings forth a possible novel approach to molecular adaptations for exercising in the heat.

\section{Exercise, Heat Exposure, and Combined Exercise-Heat Stimuli to Induce HSP90}

5.1. Heat Shock Protein 90 and Exercise. Scientific investigations of the response of HSP90 following exercise in humans are scarce. The evidence available suggests that intracellular HSP90 changes very little after exercise [78, 79]. Fehrenbach et al. [78] investigated HSP responses in leukocytes before and after a half-marathon in 12-trained endurance athletes. Heat shock protein 90 expression in peripheral blood mononuclear cells (PBMC) after a half-marathon was not different than before the race. In a similar study, Shastry et al. [79] investigated the response of HSP90 in leukocytes of trained and untrained subjects following a $1 \mathrm{~h}$ run at $70 \% \mathrm{VO}_{2 \max }$ 
in a thermoneutral environment. There was no change in HSP90 protein expression (measured by Western Blot) at 15and 24-hour after exercise compared to baseline (106 $\pm 10 \%$ and $100 \pm 11 \%$, resp.). Taken together, these studies show that, since HSP90 is unaffected after a long (half-marathon) or short ( $1 \mathrm{~h}$ ) bout of exercise, it could be concluded that exercise may have little effect on inducing an increase in HSP90 in leukocyte/PBMC. A limitation of these studies was that they used a single bout of exercise. Harris et al. [80] investigated HSP90's response to exercise training in rats by comparing an exercise group to a nonexercise group. The authors reported that, after 14 weeks of treadmill running (with progressively increasing exercise intensity), HSP90 levels were significantly increased $1.9 \pm 0.1$ (fold, $P<0.05$ ) in the soleus muscle in the exercise group compared to control rats. Perhaps regular repetitive longer exercise stimulus is required to induce HSP90 response from exercise or maybe exercise-induced response of HSP90 differ between skeletal muscle and PBMC or between species.

5.2. Heat Shock Protein 90 and Heat Exposure. Heat shock protein 90 is a heat-inducible protein indicating that stress such as heat can cause a greater intracellular protein expression. Mice, exposed to 5 days of continuous heat exposure at $37^{\circ} \mathrm{C}$, showed that HSP90 was increased in the spleen, brain, and heart tissues [81]. Wilson et al. [82] showed, using western blot technique, that, after $1 \mathrm{~h}$ of direct and constant heat exposure raising skin temperature to $41^{\circ} \mathrm{C}$, HSP90 protein was slightly increased in human skin in vivo.

5.3. Combined Exercise and Heat-Induced Heat Shock Protein 90. The evidence for induction of intracellular HSP90 in leukocytes by exercise stimulus alone is conflicting. Perhaps a combination of exercise and heat may have an additive effect to induce HSP90 expression (Figure 2). After a $10 \mathrm{~d}$ HA protocol plus an exercise intervention, McClung et al. [12] reported a $21.1 \%$ increase in HSP90 in PBMC. In ex vivo experiments of the subjects PBMCs revealed a significant correlation between inducibility of HSP90 and percent change in core temperature $\left(r^{2}=0.89, P<0.005\right)$, in that inducibility of HSP90 was increased with a lower core temperature over a $10 \mathrm{~d}$ period. Unfortunately, the aim of their study was to investigate HSP90 responses to heat and exercise and not the interaction between HSP90 and HIF1 $\alpha$; an interaction between HSP90 and HIF1 $\alpha$ could not be drawn.

We speculate that a combination of exercise and heat stress will have a synergistic effect of increasing HSP90 leading to greater HSP90-HIF1 $\alpha$ interaction. This interaction may have the physiological effect of increasing red blood cell formation and capillary density. Both these adaptations would improve oxygen-carrying capacity and increase blood flow which may increase oxygen delivery and improve exercise tolerance at altitude. It is unclear how large an increase in intracellular HSP90 is required to induce a protein-toprotein interaction to have physiological significance. In vitro studies have primarily investigated the effects of upregulation or inhibition of HSP90 but not the interaction between the two proteins. Future in vitro studies are needed to determine the optimal protein-to-protein interaction required to have a physiological effect. Using in vivo studies, researchers have used both human and animal models or different tissue samples; however they did not measure both HSP90 and HIFl $\alpha$ making it difficult to determine how much of an HSP90 increase is needed to stabilize HIF1 $\alpha[12,83]$. Future in vivo studies comparing the same tissue and species measuring HSP90-HIF1 $\alpha$ precipitate are needed to gain a better understanding of the required effect for protein-to-protein interaction and its effect on polycythemia and angiogenesis.

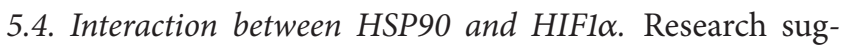
gests that heat exposure both in vitro and in vivo can induce increases in HIFl $\alpha[83,84]$ and a HSP90-HIF $\alpha$ interaction may occur [84]. Using immunofluorescence technique, Katschinski et al. [84] were the first to show in liver cancer cells (HepG2) that both HSP90 and HIF1 $\alpha$ are increased in a $42^{\circ} \mathrm{C}$ and $20 \%$ oxygen environment illustrating the effect heat has on increasing these proteins in a hot, normoxic environment. Furthermore, the administration of GA decreased HIF1 $\alpha$ protein expression. Maloyan et al. [83] added to previous findings when they reported that long-term continuous heat exposure at $34^{\circ} \mathrm{C}$ plus additional two hours of heat shock $\left(41^{\circ} \mathrm{C}\right)$ increased $\mathrm{HIF} 1 \alpha$ protein by twofold. In addition, rats in the control group that only received two hours of heat stress per day had an increase in HIFl $\alpha$ protein; however, the effect was not as great as the heatacclimated rats. Further analysis revealed that the HIF1 $\alpha$ 's downstream target transcription factor VEGF had greater mRNA expression in the acute heat-shock and long-term heat exposed group. The main finding of their investigation was that HA and/or heat stress can increase HIFl $\alpha$ protein and the downstream gene target VEGF independent of environmental hypoxia in rat myocardium [83].

Evidence from the studies of Katschinski et al. [84] and Maloyan et al. [83] bring to light a plausible mechanism in which HSP90 can stabilize HIF1 $\alpha$. A limitation of their studies $[83,84]$ is that they did not investigate the mechanism that led to the increase in HIFl $\alpha$ independent of the normoxic environment. Katschinski et al. [84] reported that HIF $\alpha$ expression was decreased during heat exposure using an HSP90 inhibitor; however, they did not report whether HSP90 inhibition decreased formation of HSP90HIF1 $\alpha$ precipitate. A reduction of HSP90-HIF1 $\alpha$ precipitate in conjunction with administration of an HSP90 inhibitor provides stronger mechanistic evidence that heat stress-induced HSP90 can regulate the activity of HIF $1 \alpha$. The proteinto-protein interaction is not clear but understanding the mechanism (phosphorylation, hydroxylation, etc.) between these two proteins may elucidate whether exercise and heatinduced increase in HSP90 will act to stabilize HIF1 $\alpha$.

The equivocal results from studies investigating HSP90s response to exercise and heat separately and/or together are compounded by different methodology. The use of various in vitro and in vivo models and the different types of tissue in which HSP90 have been measured make it difficult to draw conclusions regarding the role HSP90 may have on HIF1 $\alpha$ in humans. Nevertheless, to our knowledge, 


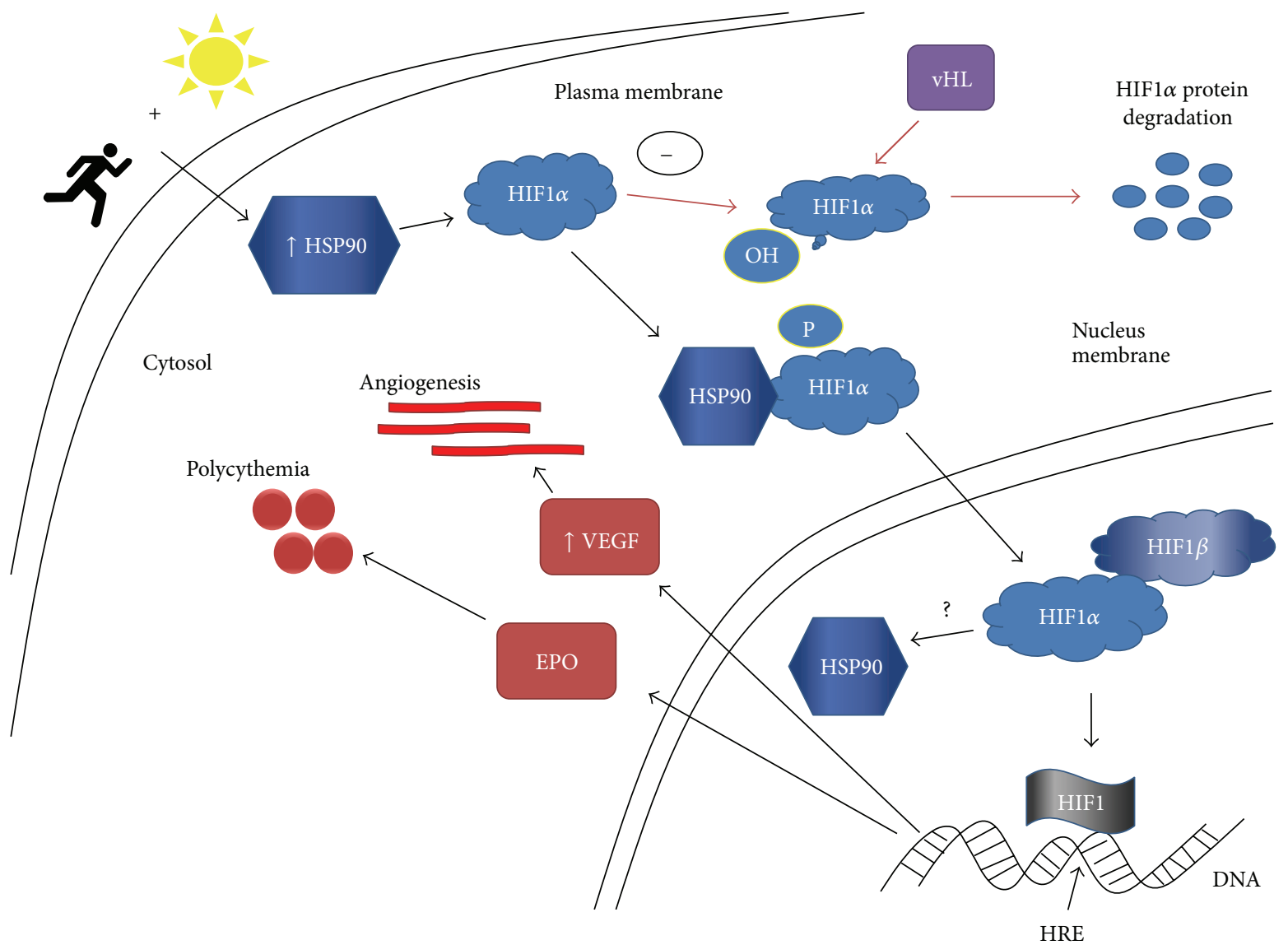

FIGURE 2: Exercise and heat exposure increases intracellular HSP90. HSP90 precipitates and phosphorylates HIF1 $\alpha$. HIFl $\alpha$ is stabilized by HSP90 independent of oxygen levels. HIFl $\alpha$ is translocated across nucleus membrane dimerizing with HIF1 $\beta$. Dimerization of HIF1 $\alpha / \beta$ increases HIF1 transcription factor which binds to HRE of DNA. This increases VEGF and EPO production. HIFl $\alpha$ : hypoxic-inducible factor $1 \alpha / \beta$; PHD: prolyl-hydroxylase; vHL: von Hippel-Lindau; VEGF: vascular endothelial growth factor; HRE: hypoxic response element.

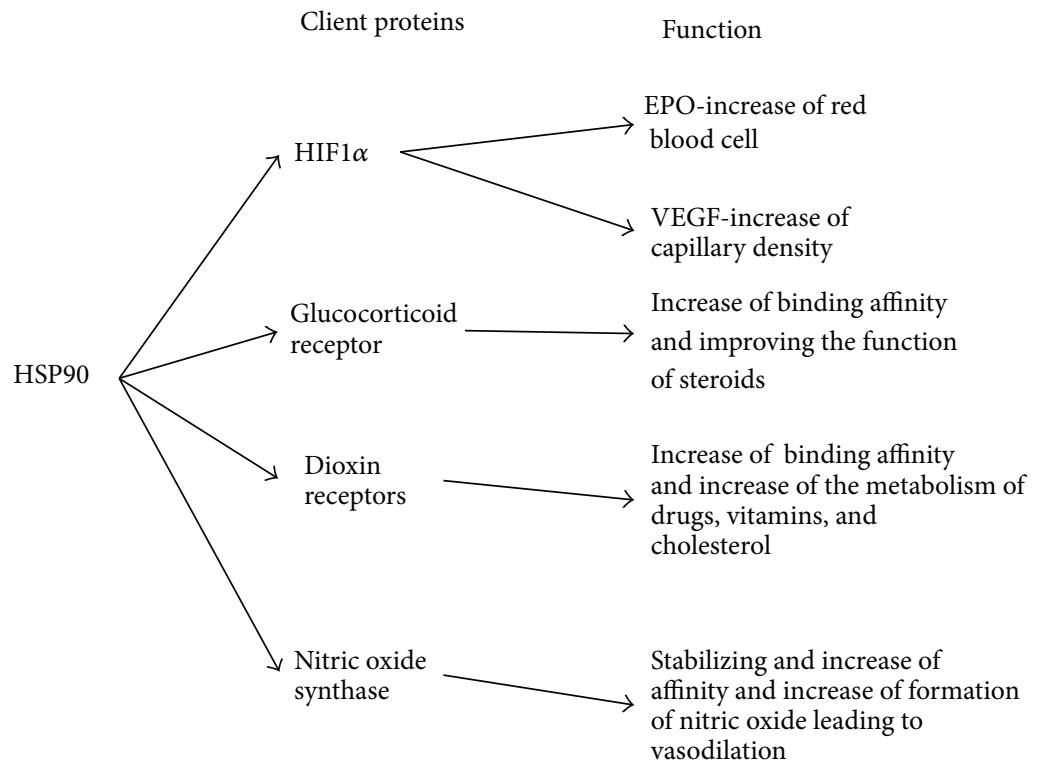

FIGURE 3: Illustration of the client proteins that HSP90 interacts with and their physiological function. 
we are the first to propose that exercising in the heat might increase HSP90-HIF1 $\alpha$ and this interaction would lead to molecular adaptations that mimic those observed in altitude acclimation. The proposed mechanism is summarized in Figure 2, however, this signaling pathway is not without limitations. First, little is known about how HSP90 interacts with HIF1 $\alpha$. Is HIF1 $\alpha$ activated by HSP90 through phosphorylation or hydroxylation or does HSP90 act as a scaffolding protein? Understanding how these two proteins interact may provide insight into HSP90's function related to HIFl $\alpha$. Second, we speculate that HSP90 would increase HIF1 $\alpha$ activity similar to how higher doses of HSP90 increased NOS activity. However, previous findings suggest that, in animal [81] and human models [12], intracellular HSP90 reaches maximal levels at 5 to $10 \mathrm{~d}$ of HA, respectively. These studies reported that subsequent heat exposure had little effect in further increasing HSP90 levels; perhaps in vivo these physiological levels are not enough to stabilize HIFl $\alpha$ in a normoxic environment as we propose. Third, most studies investigating HSP90 and HIFl $\alpha$ have been conducted in cardiac muscle, liver, prostate, PBMC, or kidney tissues both in vitro and in vivo; however, little has been done using human skeletal muscle. Caution should be used when making inferences between animal and human models. It is possible that different cell types may respond differently to heat and exercise stimulus. It is conceivable that changes in HSP90 may not be accompanied with changes in HIF1 $\alpha$ protein or gene expression in skeletal muscle compared to leukocytes [85]. Lastly, altitude-induced polycythemia is one method in which humans acclimate to altitude. This is mediated in a low oxygen environment which increases HIFl $\alpha$ leading to an increase in EPO response. In fact, Maloyan et al. have reported a fourfold increase in EPO mRNA in kidneys of rats after long-term heat exposure.

To test this hypothesis, experiments using in vivo and in vitro human skeletal muscle and PBMC models are necessary to determine the heat stress response. In the in vivo human model, HSP90, HIF1 $\alpha$ protein, EPO, and VEGF could be measured before and after a combined exercise and heat intervention. In the in vitro model, cell samples collected preand postintervention could be exposed to heat similar to the in vivo model. The same proteins would be measured, along with analysis of coimmunoprecipitate formation of HSP90HIFl $\alpha$. If coprecipitates are formed, cells would be treated with HSP90 inhibitors to determine its downstream effect on VEGF and EPO protein formation.

We propose that exercise and heat would have effects similar to those of hypoxia. Such a cross-adaptation response would be beneficial to military personnel rapidly deployed to high altitude environments, endurance athletes preparing to compete at altitude, or mountaineers preparing for high altitude expeditions. If HA induces red cell formation and vascular growth in a normoxic environment, it may enhance oxygen-carrying capacity, a limitation to exercise at altitude. Individuals would not have to travel to high altitude terrain or use costly equipment to acclimate to high altitude. Evidence suggests that prior heat exposure may be advantageous to those exercising in hypoxia. Hiestand and colleagues [86] reported that, when mice were continuously exposed to heat for 10 to $14 \mathrm{~d}$, the animals had an increased tolerance to anoxia compared to those not exposed to heat $(42.1 \pm 3.5$, $48.2 \pm 5.9$, and $54.3 \pm 4.2 \mathrm{sec}$, resp., for no heat, $10 \mathrm{~d}$ and $14 \mathrm{~d}$ of heat exposure). In humans, Heled and colleagues [87] reported that, after $12 \mathrm{~d}$ of $\mathrm{HA}\left(40^{\circ} \mathrm{C}\right.$ temperature and $40 \%$ relative humidity) at sea-level, $\mathrm{SaO}_{2}$ during walking exercise $\left(7 \mathrm{~km} / \mathrm{h}\right.$ ) at an $\mathrm{FIO}_{2}$ of $15.6 \%$ (simulated altitude of $2430 \mathrm{~m})$ was significantly improved $(86.5 \pm 2 \%$ versus $88 \pm 2 \%$ from preheat acclimation to postheat acclimation, resp.). Though the mechanism has not been investigated, perhaps HA causes adaptations to the muscle to improve muscle function [88] during exercise in hypoxia, to improve cardiovascular function enhancing exercise at altitude [89], or perhaps an increase in oxygen transport may explain the improved $\mathrm{SaO}_{2}$ observed by Heled and colleagues. There is a possible limitation to $\mathrm{HA}$. In trained individuals, $10 \mathrm{~d}$ of HA has been shown to increase plasma volume by $6.5 \%$ and increase cardiac output and stroke volume. While plasma volume expansion is beneficial at sea-level, it is possible that the hemodilution effect may limit oxygen transport, thereby decreasing $\mathrm{VO}_{2 \text { max }}$ during exercise. Research suggests that impairment of pulmonary gas exchange at altitude reduces $\mathrm{VO}_{2 \max }$ [90], so perhaps less viscous blood decreases transit time through the pulmonary system and reduces gas diffusion and oxygen transport. More work is needed to understand the possible advantages and limitations of using heat stress to improve exercise capacity at altitude.

\section{Conclusion}

The interaction between HSP 90 and HIF1 $\alpha$ from HA provides a possible novel exercise training method since the proteinto-protein interaction may promote red blood cell formation and vascular growth which are beneficial adaptations for exercise performance in a hypoxic environment. If exercising in the heat increases HSP90 and stabilizes HIF1 $\alpha$, this could be the basis for a novel cross-acclimation model where normoxic exercise in a hot environment may improve altitude tolerance. We hypothesize that the molecular adaptations during HA may benefit an athlete's performance at altitude by increasing oxygen-carrying capacity and oxygen delivery to muscles. Furthermore, perhaps this training method would be beneficial for patients who have suffered a heart attack or other conditions related to ischemia. The induction of HIFl $\alpha$ by HSP90 would signal the upregulation of EPO and VEGF leading to the formation of more red blood cells and new blood vessels. New blood vessels would be advantageous in patients with heart disease or patients with muscle wasting diseases by allowing for greater collateral circulation formation, thus increasing blood transport to ischemic tissue.

In conclusion, findings from in vitro studies suggest that HSP90 can interact with HIF1 $\alpha$ by possibly stabilizing the oxygen sensitive protein in a normoxic environment. We speculate that exercise and heat-induced upregulation of HSP90 would stabilize HIFl $\alpha$ in humans leading to an increased formation of red blood cells and vasculature in human cardiac and skeletal muscle. Nevertheless, more 
research is needed in regard to this HSP90 and HIF1 $\alpha$ interaction in humans in order to further evaluate our novel cross-adaption model.

\section{Conflict of Interests}

The authors of this paper declare that they have no conflict of interests.

\section{References}

[1] G. J. Lee, A. M. Roseman, H. R. Saibil, and E. Vierling, "A small heat shock protein stably binds heat-denatured model substrates and can maintain a substrate in a folding-competent state," The EMBO Journal, vol. 16, no. 3, pp. 659-671, 1997.

[2] G. J. Lee and E. Vierling, "A small heat shock protein cooperates with heat shock protein 70 systems to reactivate a heatdenatured protein," Plant Physiology, vol. 122, no. 1, pp. 189-197, 2000.

[3] M. M. Hutter, R. E. Sievers, V. Barbosa, and C. L. Wolfe, "Heat-shock protein induction in rat hearts: a direct correlation between the amount of heat-shock protein induced and the degree of myocardial protection," Circulation, vol. 89, no. 1, pp. 355-360, 1994.

[4] C. Prodromou, S. M. Roe, P. W. Piper, and L. H. Pearl, "A molecular clamp in the crystal structure of the N-terminal domain of the yeast Hsp90 chaperone," Nature Structural Biology, vol. 4, no. 6, pp. 477-482, 1997.

[5] S. A. Lang, D. Klein, C. Moser et al., "Inhibition of heat shock protein 90 impairs epidermal growth factor-mediated signaling in gastric cancer cells and reduces tumor growth and vascularization in vivo," Molecular Cancer Therapeutics, vol. 6, no. 3, pp. 1123-1132, 2007.

[6] A. J. Saporita, J. Ai, and Z. Wang, "The Hsp90 inhibitor, 17AAG, prevents the ligand-independent nuclear localization of androgen receptor in refractory prostate cancer cells," Prostate, vol. 67, no. 5, pp. 509-520, 2007.

[7] N. J. Mabjeesh, D. E. Post, M. T. Willard et al., "Geldanamycin induces degradation of hypoxia-inducible factor $1 \alpha$ protein via the proteosome pathway in prostate cancer cells," Cancer Research, vol. 62, no. 9, pp. 2478-2482, 2002.

[8] G. L. Semenza, "Hypoxia-inducible factor 1 (HIF-1) pathway," Science's STKE, vol. 2007, no. 407, p. cm8, 2007.

[9] S. R. Muza, B. A. Beidleman, and C. S. Fulco, "Altitude preexposure recommendations for inducing acclimatization," High Altitude Medicine and Biology, vol. 11, no. 2, pp. 87-92, 2010.

[10] C. S. Fulco, S. R. Muza, B. Beidleman et al., "Exercise performance of sea-level residents at $4300 \mathrm{~m}$ after 6 days at $2200 \mathrm{~m}$," Aviation Space and Environmental Medicine, vol. 80, no. 11, pp. 955-961, 2009.

[11] B. A. Beidleman, S. R. Muza, C. S. Fulco et al., "Seven intermittent exposures to altitude improves exercise performance at 4300 m," Medicine and Science in Sports and Exercise, vol. 40, no. 1, pp. 141-148, 2008.

[12] J. P. McClung, J. D. Hasday, J.-R. He et al., "Exercise-heat acclimation in humans alters baseline levels and ex vivo heat inducibility of HSP72 and HSP90 in peripheral blood mononuclear cells," American Journal of Physiology-Regulatory Integrative and Comparative Physiology, vol. 294, no. 1, pp. R185-R191, 2008.
[13] D. L. Riggs, M. B. Cox, J. Cheung-Flynn, V. Prapapanich, P. E. Carrigan, and D. F. Smith, "Functional specificity of cochaperone interactions with Hsp90 client proteins," Critical Reviews in Biochemistry and Molecular Biology, vol. 39, no. 5-6, pp. 279-295, 2004.

[14] Y. Fang, A. E. Fliss, D. M. Robins, and A. J. Caplan, "Hsp90 regulates androgen receptor hormone binding affinity in vivo," Journal of Biological Chemistry, vol. 271, no. 45, pp. 2869728702, 1996.

[15] K. Nadeau, A. Das, and C. T. Walsh, "Hsp90 chaperonins possess ATPase activity and bind heat shock transcription factors and peptidyl prolyl isomerases," Journal of Biological Chemistry, vol. 268, no. 2, pp. 1479-1487, 1993.

[16] J. Zou, Y. Guo, T. Guettouche, D. F. Smith, and R. Voellmy, "Repression of heat shock transcription factor HSF1 activation by HSP90 (HSP90 complex) that forms a stress-sensitive complex with HSF1," Cell, vol. 94, no. 4, pp. 471-480, 1998.

[17] A. Ali, S. Bharadwaj, R. O'Carroll, and N. Ovsenek, "HSP90 interacts with and regulates the activity of heat shock factor 1 in Xenopus oocytes," Molecular and Cellular Biology, vol. 18, no. 9, pp. 4949-4960, 1998.

[18] S. Bharadwaj, A. Ali, and N. Ovsenek, "Multiple components of the HSP90 chaperone complex function in regulation of heat shock factor 1 in vivo," Molecular and Cellular Biology, vol. 19, no. 12, pp. 8033-8041, 1999.

[19] H. Wiech, J. Buchner, R. Zimmermann, and U. Jakob, "Hsp90 chaperones protein folding in vitro," Nature, vol. 358, no. 6382, pp. 169-170, 1992.

[20] M. Minami, M. Nakamura, Y. Emori, and Y. Minami, "Both the $\mathrm{N}$ - and C-terminal chaperone sites of Hsp90 participate in protein refolding," European Journal of Biochemistry, vol. 268, no. 8, pp. 2520-2524, 2001.

[21] M. Yonehara, Y. Minami, Y. Kawata, J. Nagai, and I. Yahara, "Heat-induced chaperone activity of HSP90," Journal of Biological Chemistry, vol. 271, no. 5, pp. 2641-2645, 1996.

[22] C. Schneider, L. Seep-Lorenzino, E. Nimmesgern et al., "Pharmacologic shifting of a balance between protein refolding and degradation mediated by Hsp90," Proceedings of the National Academy of Sciences of the United States of America, vol. 93, no. 25, pp. 14536-14541, 1996.

[23] V. Thulasiraman and R. L. Matts, "Effect of geldanamycin on the kinetics of chaperone-mediated renaturation of firefly luciferase in rabbit reticulocyte lysate," Biochemistry, vol. 35, no. 41, pp. 13443-13450, 1996.

[24] L. H. Pearl and C. Prodromou, "Structure, function, and mechanism of the Hsp90 molecular chaperone," Advances in Protein Chemistry, vol. 59, pp. 157-186, 2001.

[25] D. K. Vanaja, S. H. Mitchell, D. O. Toft et al., "Effect of geldanamycin on androgen receptor function and stability," Cell Stress Chaperones, vol. 7, no. 1, pp. 55-64, 2002.

[26] A. J. Caplan, "What is a c-chaperone?" Cell Stress Chpaerones, vol. 8, no. 2, pp. 105-107, 2003.

[27] W. B. Pratt, “The hsp90-based chaperone system: involvement in signal transduction from a variety of hormone and growth factor receptors," Proceedings of the Society for Experimental Biology and Medicine, vol. 217, no. 4, pp. 420-434, 1998.

[28] H. Ogiso, N. Kagi, E. Matsumoto et al., "Phosphorylation analysis of $90 \mathrm{kDa}$ heat shock protein within the cytosolic arylhydrocarbon receptor complex," Biochemistry, vol. 43, no. 49, pp. 15510-15519, 2004. 
[29] C. Antonsson, M. L. Whitelaw, J. McGuire, J.-A. Gustafsson, and L. Poellinger, "Distinct roles of the molecular chaperone hsp90 in modulating dioxin receptor function via the basic helix-loophelix and PAS domains," Molecular and Cellular Biology, vol. 15, no. 2, pp. 756-765, 1995.

[30] I. Joab, C. Radanyi, and M. Renoir, "Common non-hormone binding component in non-transformed chick oviduct receptors of four steroid hormones," Nature, vol. 308, no. 5962, pp. 850-853, 1984.

[31] C. Radanyi, I. Joab, and J. M. Renoir, "Monoclonal antibody to chicken oviduct progesterone receptor," Proceedings of the National Academy of Sciences of the United States of America, vol. 80, no. 10, pp. 2854-2858, 1983.

[32] E. H. Bresnick, F. C. Dalman, E. R. Sanchez, and W. B. Pratt, "Evidence that the $90-\mathrm{kDa}$ heat shock protein is necessary for the steroid binding conformation of the L cell glucocorticoid receptor," Journal of Biological Chemistry, vol. 264, no. 9, pp. 4992-4997, 1989.

[33] D. Picard, "Heat-shock protein 90, a chaperone for folding and regulation," Cellular and Molecular Life Sciences, vol. 59, no. 10, pp. 1640-1648, 2002.

[34] B. Segnitz and U. Gehring, "The function of steroid hormone receptors is inhibited by the hsp90- specific compound geldanamycin," Journal of Biological Chemistry, vol. 272, no. 30, pp. 18694-18701, 1997.

[35] D. B. Solit, F. F. Zheng, M. Drobnjak et al., "17-Allylamino-17demethoxygeldanamycin induces the degradation of androgen receptor and HER-2/neu and inhibits the growth of prostate cancer xenografts," Clinical Cancer Research, vol. 8, no. 5, pp. 986-993, 2002.

[36] M. Bucci, F. Roviezzo, C. Cicala, W. C. Sessa, and G. Cirino, "Geldanamycin, an inhibitor of heat shock protein 90 (Hsp90) mediated signal transduction has anti-inflammatory effects and interacts with glucocorticoid receptor in vivo," British Journal of Pharmacology, vol. 131, no. 1, pp. 13-16, 2000.

[37] K. M. Burbach, A. Poland, and C. A. Bradfield, "Cloning of the Ah-receptor cDNA reveals a distinctive ligand-activated transcription factor," Proceedings of the National Academy of Sciences of the United States of America, vol. 89, no. 17, pp. 81858189, 1992.

[38] M. Shou, T. Lu, K. W. Krausz et al., "Use of inhibitory monoclonal antibodies to assess the contribution of cytochromes P450 to human drug metabolism," European Journal of Pharmacology, vol. 394, no. 2-3, pp. 199-209, 2000.

[39] K.-P. Kreth, K.-A. Kovar, M. Schwab, and U. M. Zanger, "Identification of the human cytochromes P450 involved in the oxidative metabolism of "Ecstasy"-related designer drugs," Biochemical Pharmacology, vol. 59, no. 12, pp. 1563-1571, 2000.

[40] M. G. Traber, D. J. Mustacich, L. C. Sullivan, S. W. Leonard, A. Ahern-Rindell, and N. Kerkvliet, "Vitamin E status and metabolism in adult and aged aryl hydrocarbon receptor null mice," Journal of Nutritional Biochemistry, vol. 21, no. 12, pp. 1193-1199, 2010.

[41] E. W. Tieu, W. Li, J. Chen, D. M. Baldisseri, A. T. Slominski, and R. C. Tuckey, "Metabolism of cholesterol, vitamin D3 and 20-hydroxyvitamin D3 incorporated into phospholipid vesicles by human CYP27A1," Journal of Steroid Biochemistry and Molecular Biology, vol. 129, no. 3-5, pp. 163-171, 2012.

[42] F. J. Gonzalez and P. Fernandez-Salguero, "The aryl hydrocarbon receptor. Studies using the AHR-null mice," Drug Metabolism and Disposition, vol. 26, no. 12, pp. 1194-1198, 1998.
[43] A. Wilhelmsson, S. Cuthill, M. Denis, A.-C. Wikstrom, J. A. Gustafsson, and L. Poellinger, "The specific DNA binding activity of the dioxin receptor is modulated by the $90 \mathrm{kd}$ heat shock protein," The EMBO Journal, vol. 9, no. 1, pp. 69-76, 1990.

[44] M. L. Whitelaw, J. McGuire, D. Picard, J.-A. Gustafsson, and L. Poellinger, "Heat shock protein hsp90 regulates dioxin receptor function in vivo," Proceedings of the National Academy of Sciences of the United States of America, vol. 92, no. 10, pp. 44374441, 1995.

[45] D. R. Bell and A. Poland, "Binding of aryl hydrocarbon receptor (AhR) to AhR-interacting protein: the role of hsp90," Journal of Biological Chemistry, vol. 275, no. 46, pp. 36407-36414, 2000.

[46] A. Kazlauskas, S. Sundström, L. Poellinger, and I. Pongratz, "The hsp90 chaperone complex regulates intracellular localization of the dioxin receptor," Molecular and Cellular Biology, vol. 21, no. 7, pp. 2594-2607, 2001.

[47] H. Li and T. L. Poulos, "Structure-function studies on nitric oxide synthases," Journal of Inorganic Biochemistry, vol. 99, no. 1, pp. 293-305, 2005.

[48] G. García-Cardeña, R. Fan, V. Shah et al., "Dynamic activation of endothelial nitric oxide synthase by Hsp90," Nature, vol. 392, no. 6678 , pp. 821-824, 1998.

[49] S. Shastry and M. J. Joyner, "Geldanamycin attenuates NOmediated dilation in human skin," American Journal of Physiology-Heart and Circulatory Physiology, vol. 282, no. 1, pp. H232-H236, 2002.

[50] Y. Song, J. L. Zweier, and Y. Xia, "Heat-shock protein 90 augments neuronal nitric oxide synthase activity by enhancing Ca2+/calmodulin binding," Biochemical Journal, vol. 355, part 2, pp. 357-360, 2001.

[51] M. Yoshida and Y. Xia, "Heat shock protein 90 as an endogenous protein enhancer of inducible nitric-oxide synthase," Journal of Biological Chemistry, vol. 278, no. 38, pp. 36953-36958, 2003.

[52] B. Z. Olenyuk, G.-J. Zhang, J. M. Klco, N. G. Nickols, W. G. Kaelin Jr., and P. B. Dervan, "Inhibition of vascular endothelial growth factor with a sequence-specific hypoxia response element antagonist," Proceedings of the National Academy of Sciences of the United States of America, vol. 101, no. 48, pp. 16768-16773, 2004.

[53] J. A. Forsythe, B.-H. Jiang, N. V. Iyer et al., "Activation of vascular endothelial growth factor gene transcription by hypoxiainducible factor 1," Molecular and Cellular Biology, vol. 16, no. 9, pp. 4604-4613, 1996.

[54] F. Koga, K. Kihara, and L. Neckers, "Inhibition of cancer invasion and metastasis by targeting the molecular chaperone heat-shock protein 90," Anticancer Research, vol. 29, no. 3, pp. 797-808, 2009.

[55] O. Alqawi, M. Moghaddas, and G. Singh, "Effects of geldanamycin on HIF-1 $\alpha$ mediated angiogenesis and invasion in prostate cancer cells," Prostate Cancer and Prostatic Diseases, vol. 9, no. 2, pp. 126-135, 2006.

[56] E. Sivridis, A. Giatromanolaki, K. C. Gatter, A. L. Harris, and M. I. Koukourakis, "Association of hypoxia-inducible factors $1 \alpha$ and $2 \alpha$ with activated angiogenic pathways and prognosis in patients with endometrial carcinoma," Cancer, vol. 95, no. 5, pp. 1055-1063, 2002.

[57] R. Bos, H. Zhong, C. F. Hanrahan et al., "Levels of hypoxiainducible factor- $1 \alpha$ during breast carcinogenesis," Journal of the National Cancer Institute, vol. 93, no. 4, pp. 309-314, 2001.

[58] A. Giatromanolaki, M. Bai, D. Margaritis et al., "Hypoxia and activated VEGF/receptor pathway in multiple myeloma," Anticancer Research, vol. 30, no. 7, pp. 2831-2836, 2010. 
[59] P. Büchler, H. A. Reber, M. Büchler et al., "Hypoxia-inducible factor 1 regulates vascular endothelial growth factor expression in human pancreatic cancer," Pancreas, vol. 26, no. 1, pp. 56-64, 2003.

[60] H. Zhong, F. Agani, A. A. Baccala et al., "Increased expression of hypoxia inducible factor- $1 \alpha$ in rat and human prostate cancer," Cancer Research, vol. 58, no. 23, pp. 5280-5284, 1998.

[61] J. S. Isaacs, Y.-J. Jung, E. G. Mimnaugh, A. Martinez, F. Cuttitta, and L. M. Neckers, "Hsp90 regulates a von Hippel Lindau-independent hypoxia-inducible factor-1 alphadegradative pathway," Journal of Biological Chemistry, vol. 277, no. 33, pp. 29936-29944, 2002.

[62] E. Minet, D. Mottet, G. Michel et al., "Hypoxia-induced activation of HIF-1: role of HIF-1 $\alpha$-Hsp90 interaction," FEBS Letters, vol. 460, no. 2, pp. 251-256, 1999.

[63] K. Gradin, J. McGuire, R. H. Wenger et al., "Functional interference between hypoxia and dioxin signal transduction pathways: competition for recruitment of the Arnt transcription factor," Molecular and Cellular Biology, vol. 16, no. 10, pp. 52215231, 1996.

[64] Y. V. Liu and G. L. Semenza, "RACK1 vs. HSP90: competition for HIF-1 $\alpha$ degradation vs. stabilization," Cell Cycle, vol. 6, no. 6, pp. 656-659, 2007.

[65] E. R. Buskirk, J. Kollias, R. F. Akers, E. K. Prokop, and E. P. Reategui, "Maximal performance at altitude and on return from altitude in conditioned runners," Journal of Applied Physiology, vol. 23, no. 2, pp. 259-266, 1967.

[66] P. E. McSharry, "Altitude and athletic performance: statistical analysis using football results," British Medical Journal, vol. 335, no. 7633, pp. 1278-1281, 2007.

[67] M. A. Goldberg and T. J. Schneider, "Similarities between the oxygen-sensing mechanisms regulating the expression of vascular endothelial growth factor and erythropoietin," Journal of Biological Chemistry, vol. 269, no. 6, pp. 4355-4359, 1994.

[68] M. A. Goldberg, C. C. Gaut, and H. F. Bunn, "Erythropoietin mRNA levels are governed by both the rate of gene transcription and posttranscriptional events," Blood, vol. 77, no. 2, pp. 271-277, 1991.

[69] M. Vogt, A. Puntschart, J. Geiser, C. Zuleger, R. Billeter, and H. Hoppeler, "Molecular adaptations in human skeletal muscle to endurance training under simulated hypoxic conditions," Journal of Applied Physiology, vol. 91, no. 1, pp. 173-182, 2001.

[70] D. Deveci, J. M. Marshall, and S. Egginton, "Relationship between capillary angiogenesis, fiber type, and fiber size in chronic systemic hypoxia," American Journal of PhysiologyHeart and Circulatory Physiology, vol. 281, no. 1, pp. H241-H252, 2001.

[71] D. Deveci, J. M. Marshall, and S. Egginton, "Chronic hypoxia induces prolonged angiogenesis in skeletal muscles of rat," Experimental Physiology, vol. 87, no. 3, pp. 287-291, 2002.

[72] G. L. Semenza, M. K. Nejfelt, S. M. Chi, and S. E. Antonarakis, "Hypoxia-inducible nuclear factors bind to an enhancer element located 3' to the human erythropoietin gene," Proceedings of the National Academy of Sciences of the United States of America, vol. 88, no. 13, pp. 5680-5684, 1991.

[73] G. L. Semenza and G. L. Wang, "A nuclear factor induced by hypoxia via de novo protein synthesis binds to the human erythropoietin gene enhancer at a site required for transcriptional activation," Molecular and Cellular Biology, vol. 12, no. 12, pp. 5447-5454, 1992.
[74] K.-U. Eckardt, U. Boutellier, A. Kurtz, M. Schopen, E. A. Koller, and C. Bauer, "Rate of erythropoietin formation in humans in response to acute hypobaric hypoxia," Journal of Applied Physiology, vol. 66, no. 4, pp. 1785-1788, 1989.

[75] B. Berglund, M. Gennser, H. Örnhagen, C. Östberg, and L. Wide, "Erythropoietin concentrations during 10 days of normobaric hypoxia under controlled environmental circumstances," Acta Physiologica Scandinavica, vol. 174, no. 3, pp. 225-229, 2002.

[76] P. O. Koistinen, H. Rusko, K. Irjala et al., "EPO, red cells, and serum transferrin receptor in continuous and intermittent hypoxia," Medicine and Science in Sports and Exercise, vol. 32, no. 4, pp. 800-804, 2000.

[77] E. Goldwasser, "Erythropoietin and the differentiation of red blood cells," Federation Proceedings, vol. 34, no. 13, pp. 22852292, 1975.

[78] E. Fehrenbach, F. Passek, A. M. Niess et al., "HSP expression in human leukocytes is modulated by endurance exercise," Medicine and Science in Sports and Exercise, vol. 32, no. 3, pp. 592-600, 2000.

[79] S. Shastry, D. O. Toft, and M. J. Joyner, "HSP70 and HSP90 expression in leucocytes after exercise in moderately trained humans," Acta Physiologica Scandinavica, vol. 175, no. 2, pp.139146, 2002.

[80] M. B. Harris, B. M. Mitchell, S. G. Sood, R. C. Webb, and R. C. Venema, "Increased nitric oxide synthase activity and Hsp90 association in skeletal muscle following chronic exercise," European Journal of Applied Physiology, vol. 104, no. 5, pp. 795-802, 2008.

[81] H. Sareh, M. E. Tulapurkar, N. G. Shah, I. S. Singh, and J. D. Hasday, "Response of mice to continuous 5-day passive hyperthermia resembles human heat acclimation," Cell Stress and Chaperones, vol. 16, no. 3, pp. 297-307, 2011.

[82] N. Wilson, A. McArdle, D. Guerin et al., "Hyperthermia to normal human skin in vivo upregulates heat shock proteins 27 , 60, 72i and 90," Journal of Cutaneous Pathology, vol. 27, no. 4, pp. 176-182, 2000.

[83] A. Maloyan, L. Eli-Berchoer, G. L. Semenza, G. Gerstenblith, M. D. Stern, and M. Horowitz, "HIF- $1 \alpha$-targeted pathways are activated by heat acclimation and contribute to acclimationischemic cross-tolerance in the heart," Physiological Genomics, vol. 23, no. 1, pp. 79-88, 2005.

[84] D. M. Katschinski, L. Le, D. Heinrich et al., "Heat induction of the unphosphorylated form of hypoxia-inducible factor-1 $\alpha$ is dependent on heat shock protein-90 activity," Journal of Biological Chemistry, vol. 277, no. 11, pp. 9262-9267, 2002.

[85] R. Mounier, V. Pialoux, B. Roels et al., "Effect of intermittent hypoxic training on HIF gene expression in human skeletal muscle and leukocytes," European Journal of Applied Physiology, vol. 105, no. 4, pp. 515-524, 2009.

[86] W. A. Hiestand, F. W. Stemler, and R. L. Jasper, "Increased anoxic resistance resulting from short period heat adaptation," Proceedings of the Society For Experimental Biology and Medicine, vol. 88, no. 1, pp. 94-95, 1955.

[87] Y. Heled, A. Peled, R. Yanovich et al., "Heat acclimation and performance in hypoxic conditions," Aviation, Space, and Environmental Medicine, vol. 83, no. 7, pp. 649-653, 2012.

[88] M. N. Sawka, K. B. Pandolf, B. A. Avellini, and Y. Shapiro, "Does heat acclimation lower the rate of metabolism elicited by muscular exercise?" Aviation Space and Environmental Medicine, vol. 54, no. 1, pp. 27-31, 1983. 
[89] A. C. White, R. M. Salgado, S. Schneider et al., "Does heat acclimation improve exercise capacity at altitude? A crosstolerance model," International Journal of Sports Medicine, 2014.

[90] J. A. L. Calbet, R. Boushel, G. Rådegran, H. Søndergaard, P. D. Wagner, and B. Saltin, "Determinants of maximal oxygen uptake in severe acute hypoxia," American Journal of Physiology-Regulatory Integrative and Comparative Physiology, vol. 284, no. 2, pp. R291-R303, 2003. 

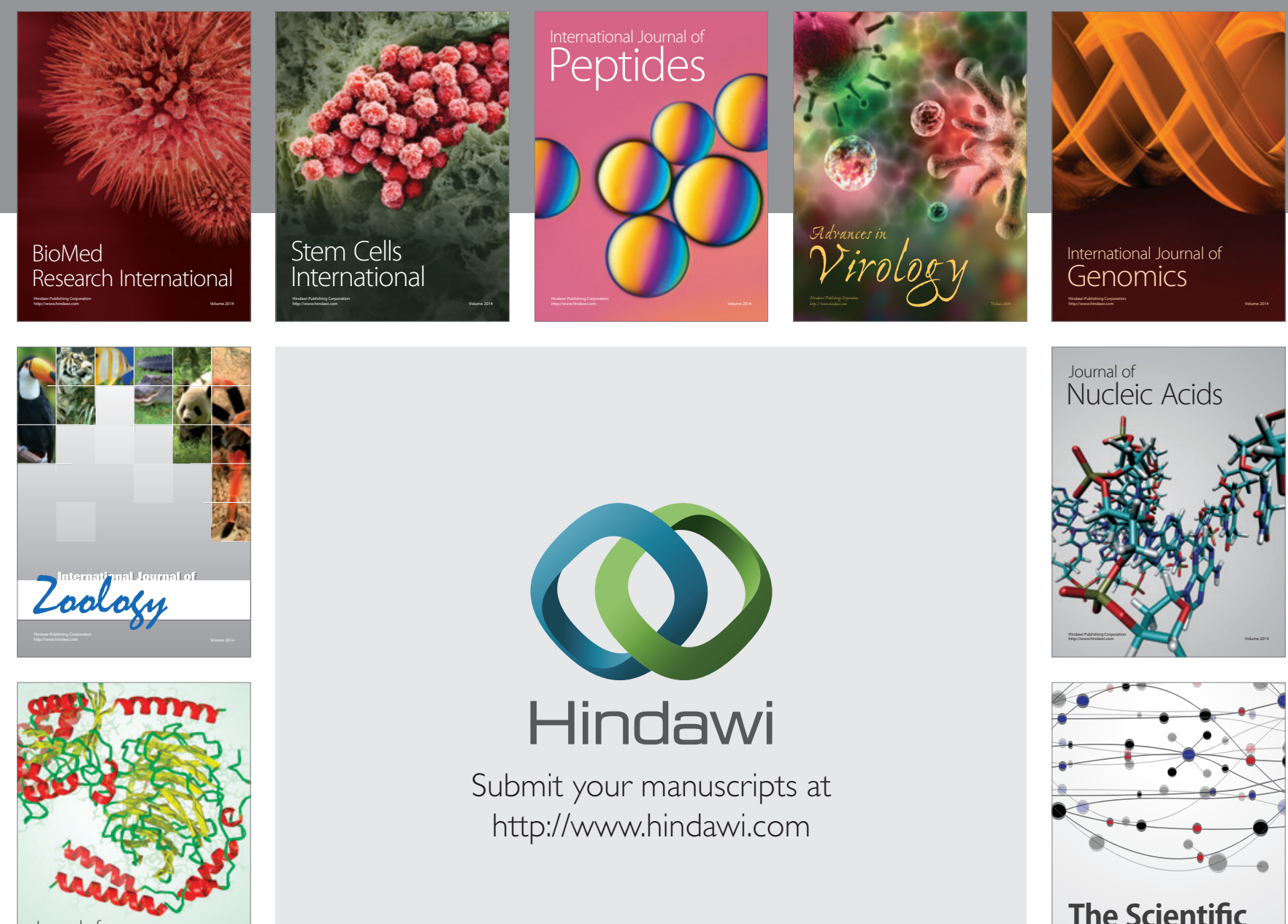

Submit your manuscripts at

http://www.hindawi.com

Journal of
Signal Transduction
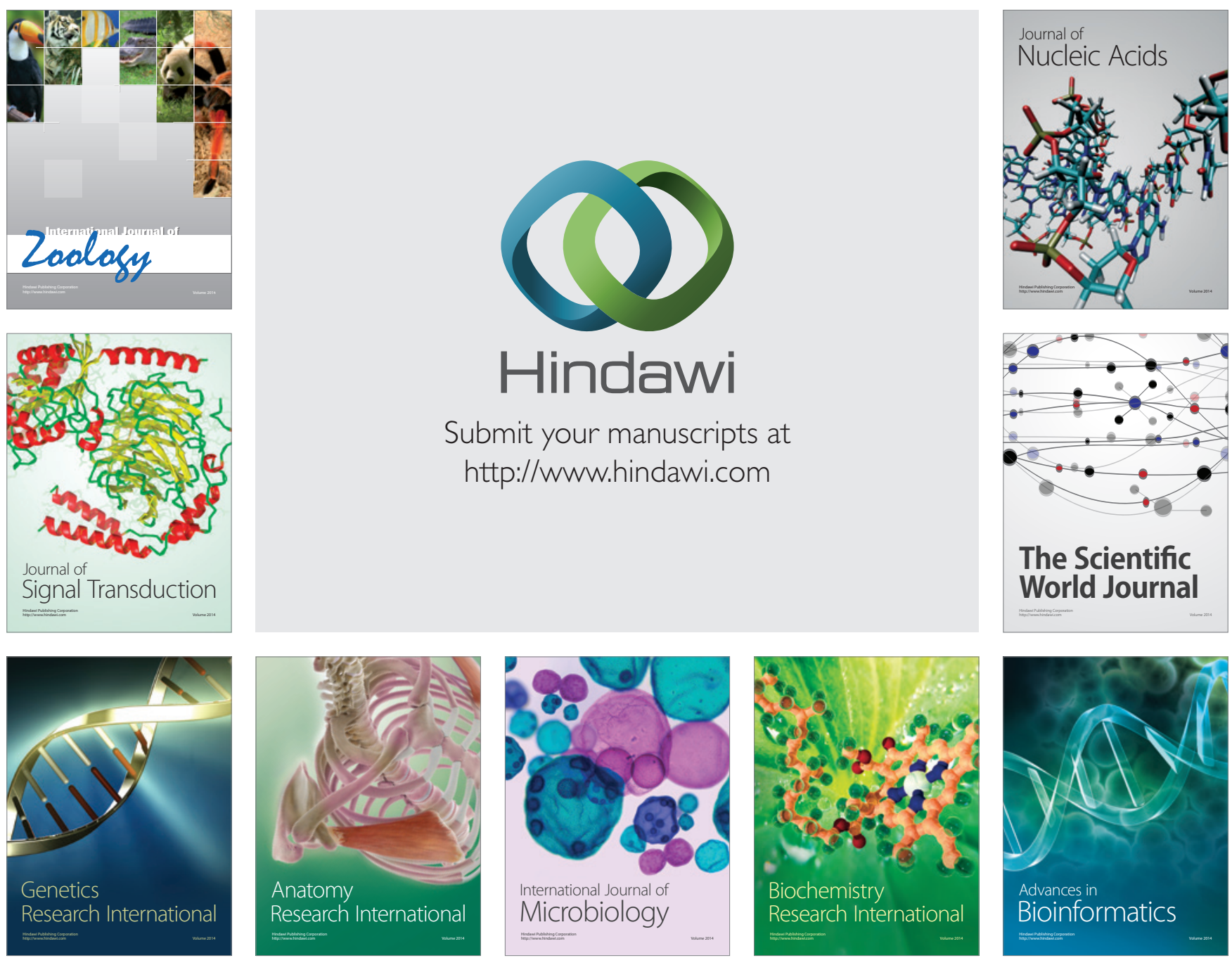

The Scientific World Journal
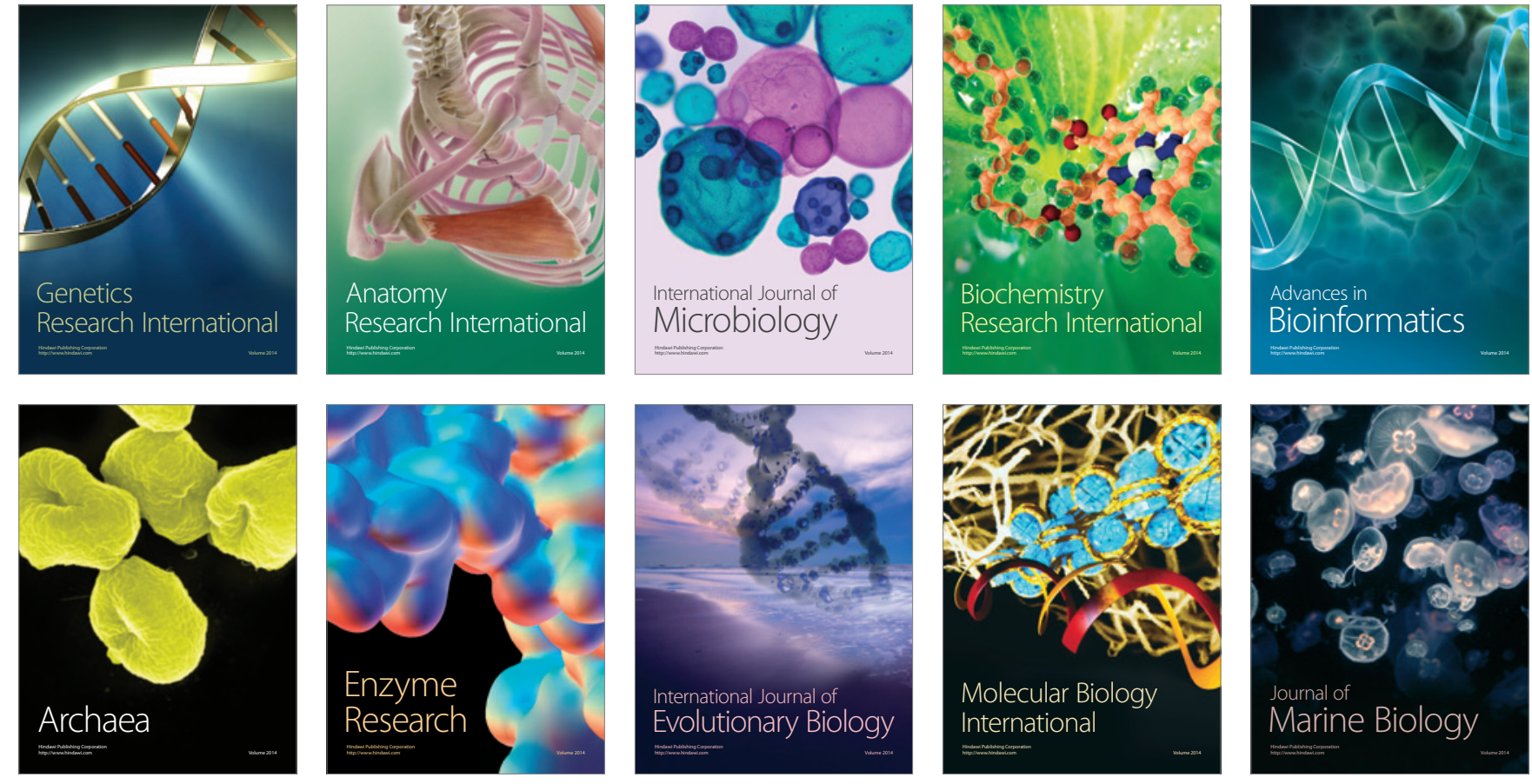